\title{
The Need for Uniqueness among Gulf Cooperation Council Countries' Consumers: A Cross-Culture Study
}

\author{
Sarah G. Alzahrani ${ }^{1} \&$ Lauren (Reiter) Copeland ${ }^{2}$ \\ ${ }^{1}$ King Abdulaziz University, Jeddah, Saudi Arabia \\ ${ }^{2}$ Kent State University, Kent, OH, USA \\ Correspondence: Sarah G. Alzahrani, Assistant Professor, Fashion Design Department, College of Art and design, \\ King Abdulaziz University, Jeddah, Saudi Arabia. E-mail: sgalzahrani@kau.edu.sa
}

Received: July 6, 2017 Accepted: July 22, 2017 Online Published: July 28, 2017

doi:10.5539/ijms.v9n4p29 URL: http://doi.org/10.5539/ijms.v9n4p29

\begin{abstract}
Understanding differences among consumers across varying cultures is of great importance to the success of international retailers. Ignoring the influence of culture and centralized marketing has led to a decline in profits for some international companies. Studying the culture of Middle East countries, particularly the Gulf Cooperation Council Countries (GCCC), Saudi Arabia, United Arab Emirates, Kuwait, Bahrain, Qatar, and Oman, is essential before marketing in these countries. Additionally, the GCCC is one of the top 10 luxury markets in the world. Hofstede model of national culture is crucial for GCCC due to the fact culture norms regarding dress and appearance are nationally adopted. A sample of 170 participants from the GCCC was collected using an online questionnaire of 45 items measuring national culture dimensions and need for uniqueness when shopping for luxury goods. It was found that power distance in all GCCC countries was a significant predictor of having a need for uniqueness, as well as indulgence. Power distance had a positive relationship with the need for uniqueness while indulgence had a negative relationship with the need for uniqueness. For other dimensions, findings indicated that long term vs short term orientation, masculinity, uncertainty avoidance, and individualism were not significant predictors leading to uniqueness. Additionally, the important construct for uniqueness among GCCC consumers is unpopular choice followed by avoiding similarity. Creative choice is less important among the three constructs of uniqueness for GCCC participants.
\end{abstract}

Keywords: Gulf Cooperation Council Countries, culture, Hofstede, dimensions, uniqueness

\section{Introduction}

Understanding differences among consumers across varying cultures is important for the success of international retailers. Ignoring the impact of culture and centralized marketing has led to a decline in profits for some international companies. Studying the culture of the Middle East countries, particularly the Gulf Cooperation Council Countries (GCCC), Saudi Arabia, United Arab Emirates, Kuwait, Bahrain, Qatar, and Oman, is essential before marketing in these countries. The GCCC is one of the top 10 luxury markets in the world (Consultancy.uk, 2014). United Arab Emirates alone increased from 12th, in 2003, to 8th, in 2008, among top global apparel importers (Kunz \& Garner, 2011). According to Euromonitor (2017) the best performing luxury products in the country encompass several apparel categories including luxury leather goods, jewelry and timepieces, super premium beauty and personal care, designer apparel and footwear (ready-to-wear) and luxury accessories. This is driven by the consumer demand in the region of high quality and brand names goods (Euromonitor, 2017).

Retailers target these six countries of GCCC more than others in the same region as a consequence of the fast growing economy striving quickly towards high levels of wealth and modern life after discovering oil. These six countries with an average per capita GDP of more than $\$ 70$ thousand are an attractive market to apparel retailers (Amadeo, 2016). According the UAE ministry of the economy the country's GDP has doubled in ten years from 1999-2009 with luxury being a main focal point to average consumer in the region (IMF, 2009). To ensure the success of retailing in these countries, retailers and marketers need to examine how consumers in these countries respond to new products and how culture impacts consumers' purchase intentions and behaviors. Takada \& Jain (1991) report that cultural differences of consumers do affect their purchase decisions. In addition, individual need for uniqueness motivates consumers to go as far as to change their outward appearance. Vel, Captain, Al-Abbas, \& Al Hashemi (2011) also note that family members and peers are the main contributors to a member 
of this regions willingness to purchase luxury products. The high need for uniqueness motivates people to adapt new styles in order to differentiate themselves from others (Workman \& Kidd, 2000). Additionally Asshidin, Abidin, \& Borhan, (2016) conducted research to better understand consumer attitude and uniqueness toward international products and found that high quality is of great importance and uniqueness positively influences attitudes among consumers. In Japan Knight \& Kim (2007) found that creative choice was positively related to emotional value of product. Additionally need for uniqueness was considered imperative moving forward in future studies regarding better understanding of how to market to generation Y.

Therefore, the present study aims to understand how consumers within the GCCC are different in their need for uniqueness by applying Hofstede \& Hofsted's (2001) model of national culture (Hofstede MNC). Vel et al. (2011) call for more research regarding the better understanding of the luxury market in this area and state that "Owning luxury products reflected one's personality, social image, and their position in this society" (p. 1). Currently, limited apparel consumer behaviour studies have focused on uniqueness theory in relation to the consumers of the GCCC.

\section{Review of Literature}

\subsection{Uniqueness Theory}

According to uniqueness theory (Workman \& Kidd, 2000), people have a moderate level of similarity relative to others. A moderate level of similarity causes positive emotional reactions among people, which then causes a constant in behavior without any change. Any increase or decrease relative to the moderate level of similarity motivates a person to have a negative emotional reaction; as a result, a change in behavior occurs. For instance, when the degree of similarity exceeds the moderate range, a person feels a very high degree of similarity relative to others. In the case of a high need for uniqueness, a person would have a negative emotional reaction, leading him to change his behavior toward dissimilarity. The negative emotional reaction might occur as well because the degree of similarity falls below the moderate range. A person with low need for uniqueness would feel a very slight degree of similarity and change his behavior toward similarity (Snyder \& Fromkin, 1980; Workman \& Kidd, 2000).

\subsection{Hofstede and Hofstede's Dimension of National Culture}

Hofstede \& Hofstede's (2001) study of national culture differences is based on data collected in 71 countries by the International Business Machines (IBM) Corporation. IBM had subsidiaries in all countries around the world. It manufactured and sold high-technology products such as computers. IBM employed almost exclusively nationals of the countries studied (Hofstede \& Hofstede, 2001). IBM was an organization with a unified group of products and employments; that lead to having comparable samples of employees who only were different in nationality (Hofstede \& Hofstede, 2001). The employees responded to surveys held between 1967 and 1973 in 20 languages. Four dimensions of "national culture, power distance, masculinity, individualism, and uncertainty avoidance" were found through an eclectic analysis of data (Hofstede, Hofstede, \& Minkov, 2013, p. 31). Later, in the 1980s, Bond and Hofstede found "long-term versus short term" dimension (Hofstede \& Hofstede, 2001). More recently, "indulgence versus restraint" was added (Hofstede et al., 2013, p. 29). Hofstede \& Hofstede's (2001) MNC has been criticized for assuming that nations embrace one culture. However, for GCCC, Hofstede and Hofstede's MNC is crucial due to the fact culture norms around dress and appearance are nationally adopted (Tawfiq \& Ogle, 2013).

\subsection{Relationship between National Culture and the Need for Uniqueness}

Uniqueness as a human characteristic differs among societies and individuals. Physically, each individual has a particular genetic pool moulding the origin of his/her uniqueness. Socially, good or bad norms are general standards that have formalized within a society. People are rewarded for compliance to norms and punished for deviations from norms (Snyder \& Fromkin, 1980). Conformity to a group in order to get social approval or avoid disapproval costs people their individuality. When people deny one activity to engage in another activity to fit within a group, they oftentimes feel a high degree of similarity that threatens their uniqueness (Snyder \& Fromkin, 1980). People need to conform and fit, as well as to be different and unique among one another (Lynn \& Harris, 1997). To have a balance between the need for uniqueness and the need for conformity, people tend to show their uniqueness within an acceptable level of deviation from norms found in their society (Snyder \& Fromkin, 1980). People may manifest their differences through uniqueness attributes, including possessing commodities. According to commodity theory (Marx, 1867), when a commodity is unavailable for the public, people with high need for uniqueness seek to possess these commodities. 


\subsubsection{What Motivates Uniqueness?}

Imhoff \& Erb (2009) empirically found that having choices and alternatives fulfil people need for uniqueness and eliminate its effect on the majority of people. People tend to find a position supported by the majority unattractive and then refuse its influence. Therefore, the need for uniqueness is a result of refusing an unattractive position of majority and not a result of rejecting the majority influence itself. According to Simonson \& Nowlis (2000), consumer's purchase decisions can be significantly affected by the need for uniqueness. In addition, Imhoff \& Erb (2009) concluded that the need for uniqueness may collide with other concerns such as intercultural differences. Imhoff \& Erb (2009) recommended studying cultures to better understand how individuals distinguish themselves within their societies and to better predict differences in people's behaviors.

\subsubsection{Power Distance}

Hofstede explain power distance to be "a measure of interpersonal power or influence between boss and subordinate as perceived by the less powerful of the two, subordinate" (Hofstede \& Hofstede, 2001, p. 83). In societies with high power distance, individuals are agreeable with the hierarchy of power and do not want to resist. According to Hofstede et al. (2013), people in large power distance societies, are obedient towards authority and willing to follow the rules. They have low level of acceptance toward innovativeness and no interest in solving their problems through innovation. The reason behind this is possibly the lack of opportunities to make decisions or stability found in the moderate level of similarity relative to other people (Hsu, Hsu, \& Yeh, 2010). As a result, we propose that: H1: The larger the power distance of a national culture is, the lower need for uniqueness will be among GCCC consumers.

\subsubsection{Individualism}

Individualism refers to people's desire to be individuals rather than part of a group. In collectivist societies, people live with extended families and harbour a strong loyalty for their close knit group, not toward politics. People in collectivist societies are more likely to follow norms (Hofstede et al., 2013). Conversely, people in individualistic societies are independent, rely on themselves, and their relationships with others are loose. Thus, they are more likely to adopt new products. People in collectivist societies are more likely to wait, for example in terms of adapting new items, until these new phenomena become popular among larger groups of people. This unhurried mentality in adapting new items might also refer to the stability of the moderate level of similarity relative to others. Previous studies show a strong relationship between acceptance toward innovativeness and individualism (Hsu et al., 2010). Thus, the second hypothesis is hereby ascertained: H2: The large individualism of a national culture is, the larger need for uniqueness will be among GCCC consumers.

\subsubsection{Masculinity}

People in masculine societies are independent and characterized to ignore other people's responses. As a result, people in masculine societies are expected to take the risk of trying innovativeness and to violate norms. Thus, consumers in masculine societies are more likely to adapt new styles in order to be different (Hofstede et al., 2013). Conversely, people in feminine societies are expected to follow norms in order to look like and be identified with others. This concept reflects a stable level of similarity upon individuals relative to others. In the current study, applying Hofstede \& Hofstede's (2001) culture dimensions leads to the statement that members of a masculine society have unstable levels of similarity relative to others which motivates them to change their appearance in order to look different. As a result, the third hypothesis of this study is: H3: The large masculinity of a national culture is, the larger need for uniqueness will be among GCCC consumers.

\subsubsection{Uncertainty Avoidance}

People in an uncertainty avoidance society look for structure in their life to make events more predictable. They avoid unstructured, unknown, and unusual situations and view new things as precarious. As a result, people in high uncertainty avoidance society are more likely to avoid new things or be late to adapt new items. This willingness to avoid adapting new things might be a result of having a moderate/low level of similarity to other people (Hofstede et al., 2013). Thus, the forth hypothesis is proposed: H4: The large uncertainty avoidance of a national culture is, the lower need for uniqueness will be among GCCC consumers.

\subsection{6 "Long-Term Orientation versus Short-Term Orientation"}

Members of a long-term orientation society are more likely to adopt a future-oriented thinking and attitude. In contrast, short-term orientation societies respect the concept of tradition highly and thus reject any change regarding their appearance (Hofstede et al., 2013, p. 239), As a result, the fifth hypothesis is: H5: The large long-term orientation of a national culture is, the larger need for uniqueness will be among GCCC consumers. 


\subsubsection{Indulgence versus Restraint}

Indulgence stands for a tendency to allow gratification of basic activities related to having fun and enjoyable life. According to Hofstede, Hofstede, \& Minkov (2013), a more indulgent society will be more inclined toward unrestrained consumption. They tend to consume more items than others in a restrained society. The reason behind this could be the instability of the moderate level of similarity relative to other people which motivates them to adopt different styles. Therefore, the sixth hypothesis was constructed: H6: The larger the indulgence of a national culture is, the larger need for uniqueness will be among GCCC consumers.

\subsubsection{People's Need for Uniqueness}

According to Tian, Bearden, \& Hunter (2001), the need for uniqueness is explained in the following behavioural dimensions; "creative choice counter-conformity, unpopular choice counter-conformity, and avoidance of similarity" (p. 52). Creative choice counter-conformity refers to people's desire to purchase products that differentiate them from others but that products still considered good choices by others. Consumers with this attitude are able to solve consumption problems by thinking outside of the box. This ability is impacted by several factors including level of education, personality, age, and life experiences. Thus, the seventh hypothesis of the study is: H7: Creative choice counter-conformity is significantly different among GCCC consumers.

Second, unpopular choice counter-conformity indicates people's desire to establish their difference from other by selecting products that challenge society norms. Consumers within this dimension are subjects of society disapproval and criticism. People tendency to make purchase decisions that others might criticize shows apathy about criticism. This attitude could be affected by factors such as age, gender, economic status which led to the eighth hypothesis of this study: H8: Unpopular choice counter-conformity is significantly different among GCCC consumers.

Finally, avoidance of similarity refers to the situation when consumers challenge norms to be different from others by avoiding common and undistinguished items. To be distinguished from others, consumers may create a style by combining apparel in unusual ways, purchase antique items, or shop in discontinued stores (Tian et al., 2001). The ability of avoidance of similarity could be affected by several factors including economic status or the availability of opportunities to make decisions. Thus, the ninth hypothesis of this study was proposed: $H 9$ : Avoidance of similarity is significantly different among GCCC consumers.

\section{Methodology}

A sample from all GCCC countries was collected using an online anonymous questionnaire given to respondents through Qualtrics. The questionnaire was designed to test the national culture dimensions and the need for uniqueness. To measure national culture dimensions, Values Survey Module (VSM 2013) by Hofstede, Hofstede, Minkov \& Vinken (2013) was utilized. The survey included 30 items to compare culturally influenced values of respondents. The survey allowed scores to be computed on six dimensions of national culture, four questions for each dimension with a five point Likert scale $(1=$ most important, $5=$ very important). The other six questions asked for demographic information. In addition, to measure the need for uniqueness among the participants, a scale developed by Miremadi, Fotoohi, Sadeh, Tabrizi, and Javidigholipourmashhad (2011) was adapted. The scales included 15 items to measure the constructs of the need for uniqueness; "creative choice counter-conformity, unpopular choice counter-conformity, and avoidance of similarity" (Tian, Bearden, \& Hunter, 2001, p. 52). The measures for creative choice included items such as "self-customization of product or brand" and "individuality expression by the product or brand." Unpopular choice was measured by items such as "dress differently" and "breaking customs and rules" while the measures for avoidance of similarity included items for instance "disliking customarily purchased products or brands" and "devaluation of products or brands that are regularly purchased by everyone." Each construct was measured by five questions each on a seven point Likert scale $(1=$ strongly disagree, $7=$ strongly agree $)$.

Multiple linear regressions (hypotheses 1-6) see figure 1 and one way ANOVA's (hypotheses 7-9) see figure 2, were conducted to understand the relationships between the GCCC individual countries and their needs based on Hofstede \& Hofstede's (2001) theory. SPSS version 22.0 was utilized and reliability was measured. 


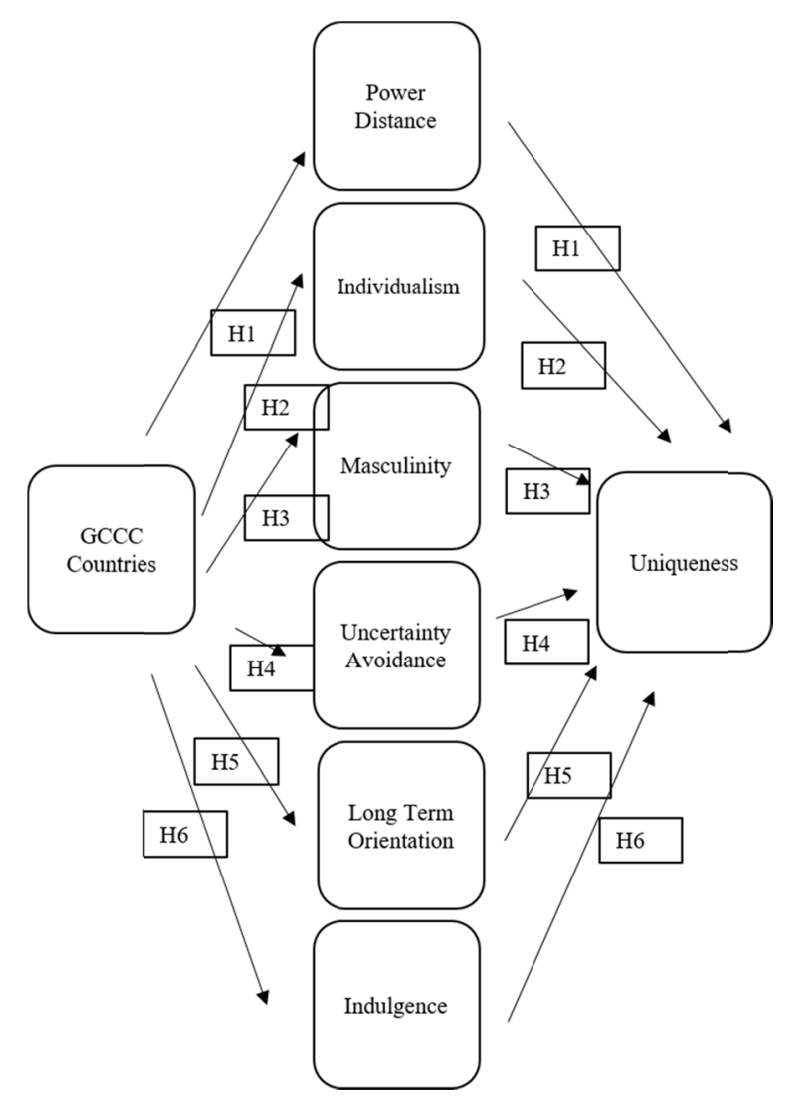

Figure 1. Linear regressions (Hypotheses 1-6) leading to uniqueness among GCC countries
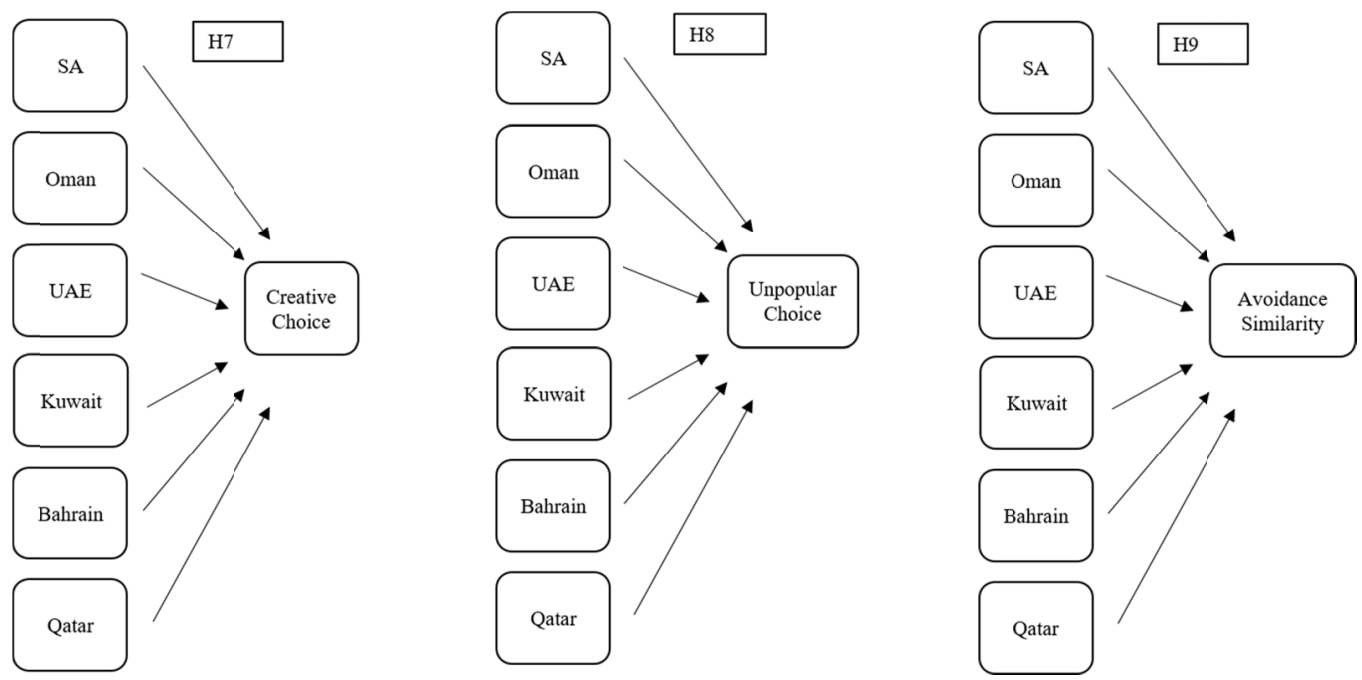

Figure 2. One way ANOVA (Hypotheses 7-9) choice needs in GCC countries

\section{Findings}

A total of 170 responses by GCCC citizens were collected and analyzed. Of the participants $60.6 \%$ were female $(n=103)$. A majority of the population was between the ages of 40-49 years old $(n=34)$ followed by $35-39,25-29$, and 30-34 years (all $n=22), 20-24$ years $(n=19)$, under 20 years old $(n=9), 50-59$ years old $(n=4)$ and 60 years or over $(\mathrm{n}=1)$. Regarding education over half of the respondents in this study had 14 years of schooling or more $(n=95)$ with the remaining having 13 years of school and under or unidentified themselves $(n=75)$. A majority of participants in this study had no paid full time job and were considered students $(n=34)$ followed by managers of managers $(n=25)$, Managers of subordinates $(n=22)$ and academically trained professionals $(n=27)$. The 
remaining participants were either unidentified or were considered unskilled with general skills that they had been trained regarding $(n=62)$. Of the respondents in this study 37 participants chose to be unidentified in their demographic responses. However, the researchers deemed their answers regarding the items measuring the purpose of the study to be valid and useful for certain hypotheses posed. The majority of respondents in this study are from Saudi Arabia ( $\mathrm{n}=66)$ followed by Oman $(\mathrm{n}=23)$, Qatar $(\mathrm{n}=14)$, Bahrain $(\mathrm{n}=13)$, United Arab Emirates $(\mathrm{n}=10)$, Kuwait $(\mathrm{n}=5)$. See table 1 for a demographic break down of participants.

Table 1. Demographics of sample population $(\mathrm{n}=176)$

\begin{tabular}{|c|c|c|c|}
\hline & & $\mathbf{n}$ & $\%$ \\
\hline \multirow[t]{3}{*}{ Gender } & Male & 30 & 17.6 \\
\hline & Female & 103 & 60.6 \\
\hline & Unidentified & 37 & 21.8 \\
\hline \multirow[t]{9}{*}{ Age } & Under 20 years & 9 & 5.3 \\
\hline & 20-24 years & 19 & 11.2 \\
\hline & $25-29$ years & 22 & 12.9 \\
\hline & $30-34$ years & 22 & 12.9 \\
\hline & $35-39$ years & 22 & 12.9 \\
\hline & $40-49$ years & 34 & 20.0 \\
\hline & $50-59$ years & 4 & 2.4 \\
\hline & 60 or over & 1 & .6 \\
\hline & Unidentified & 37 & 21.8 \\
\hline \multirow[t]{10}{*}{ Education } & 10 years or less & 2 & 1.2 \\
\hline & 11 years & 3 & 1.8 \\
\hline & 12 years & 27 & 15.9 \\
\hline & 13 years & 6 & 3.5 \\
\hline & 14 years & 11 & 6.5 \\
\hline & 15 years & 10 & 5.9 \\
\hline & 16 years & 29 & 17.1 \\
\hline & 17 years & 16 & 9.4 \\
\hline & 18 years or over & 29 & 17.1 \\
\hline & Unidentified & 37 & 21.8 \\
\hline \multirow[t]{8}{*}{ Occupation } & No paid job (full time students) & 34 & 20.0 \\
\hline & Unskilled or semi-skilled worker & 2 & 1.2 \\
\hline & Generally trained office worker or secretary & 11 & 6.5 \\
\hline & $\begin{array}{l}\text { Vocationally trained craftsperson, technician, } \\
\text { IT-specialist, nurse }\end{array}$ & 12 & 7.1 \\
\hline & $\begin{array}{l}\text { Academically trained professional or } \\
\text { equivalent (not a manger of people) }\end{array}$ & 27 & 15.9 \\
\hline & $\begin{array}{l}\text { Manage of one or more subordinates (not } \\
\text { managers) }\end{array}$ & 22 & 12.9 \\
\hline & Manager of one or more managers & 25 & 14.7 \\
\hline & Unidentified & 37 & 21.8 \\
\hline \multirow[t]{7}{*}{ Country } & Saudi Arabia & 66 & 38.8 \\
\hline & Bahrain & 13 & 7.6 \\
\hline & Kuwait & 5 & 2.9 \\
\hline & Oman & 23 & 13.5 \\
\hline & Qatar & 14 & 8.2 \\
\hline & United Arab Emirates & 10 & 5.9 \\
\hline & Unidentified & 39 & 22.9 \\
\hline
\end{tabular}

Due to the fact that there were a limited number of items in the scale and that it was found difficult to the collect a homogenous sample between countries, Cronbach's alpha was found to be low for the cultural dimensions. Reliability of power distance was .51 , individualism was .51 , masculinity was .56 , uncertainty Avoidance was .50 , indulgence was .58 , and long term orientation was .62. Further data with the scales and GCCC needs to be investigated to better understand the reliability of these measures. Reliability of "creative choice, unpopular choice, and avoidance similarity" based on Cronbach's alpha were high, $.90, .95$, and .96 respectively.

Linear regressions were conducted to determine hypotheses one through six. It was found that power distance in all GCCC was a significant predictor of having a need for uniqueness as well as indulgence $\left(\mathrm{R}^{2}=.29\right)$. According 
to the results of this study, the power distance had positive relationship with the need for uniqueness while indulgence had a negative relationship with the need for uniqueness. For other dimensions, the findings indicated that "individualism, masculinity, uncertainty avoidance, and long term vs short term orientation" were not significant predictors leading to uniqueness. Therefore hypotheses 1 through 6 were not accepted. The findings of this studies contrast with Hsu et al. (2010) study that indicates a negative relationship between power distance and avoidance of uncertainty with the level of acceptance toward innovativeness. Hsu et al. (2010) study also reports a positive relationship of other dimensions, individualism, masculinity, and long term vs short term orientation with the level of acceptance toward innovations and the need to be different. See Table 2 for a breakdown of findings.

Table 2. Uniqueness among GCCC consumers

\begin{tabular}{llll}
\hline Variable Leading to Uniqueness & $\boldsymbol{\beta}$ & $\mathbf{t}$ & sig. \\
\hline H1 Power Distance & .35 & 4.62 & $.00^{* *}$ \\
H2 Individualism & -.01 & -.10 & .92 \\
H3 Masculinity & -.01 & -.17 & .86 \\
H4 Uncertainty Avoidance & .13 & 1.62 & .11 \\
H5 Long Term Orientation & .12 & 1.36 & .18 \\
H6 Indulgence & -.17 & -2.39 & $.02^{*}$ \\
\hline
\end{tabular}

Hypotheses 7, 8, and 9 were conducted using one way ANOVA to determine the difference between GCCC nationality and type of uniqueness including "creative choice, unpopular choice, and avoidance similarity". There was a significant difference between groups regarding all three analyses conducted $(p<.000)$ leading to the last three hypotheses of the study to be accepted. To understand the meaning of uniqueness of the participants in the GCCC, the mean scores of the three uniqueness constructs are compared. The means for unpopular choice for SA, Oman, UAE, Kuwait, Bahrain, and Qatar are 22.89, 23.42, 21.58, 25.20, 22.62, and 21.39 respectively. Avoiding similarity means are $16.18,17.67,15.40,18.24,18.86$, and 13.19 while the means for creative choice are 14.2, 15.03, 11.80, 17.40, 17.47, and 11.49 for GCCC in the same countries order above. This order shows that participants in this study express their uniqueness in similar way with different weight for each construct. According to the findings of the current study, unpopular choice is the important construct for uniqueness among GCCC consumers, followed by avoiding similarity. Creative choice is less important among the three constructs of uniqueness for GCCC participants. Miremadi et al. (2011) study reports different order in the important of each contrast. This early study reveals that the important constructs for uniqueness among Iranian participants are creative choice, similarity avoidance, and unpopular choice respectively. See Table 3 for a breakdown of findings of this study.

Table 3. Choice relating to GCCC consumers

\begin{tabular}{|c|c|c|c|c|c|c|c|c|}
\hline $\begin{array}{l}\text { Choice } \\
\text { Variable } \\
\end{array}$ & Country & $n$ & $\mathbf{M}$ & Std. Dev. & $S S$ & Mean Sq. & $\mathbf{F}$ & sig \\
\hline H7 & SA & 66 & 14.2 & 5.04 & \multirow{6}{*}{3383.70} & \multirow{6}{*}{563.95} & \multirow{6}{*}{14.89} & \multirow{6}{*}{$.000 *$} \\
\hline Creative & Oman & 23 & 15.03 & 6.88 & & & & \\
\hline \multirow[t]{4}{*}{ Choice } & UAE & 10 & 11.80 & 5.20 & & & & \\
\hline & Kuwait & 5 & 17.40 & 5.98 & & & & \\
\hline & Bahrain & 13 & 17.47 & 5.33 & & & & \\
\hline & Qatar & 14 & 11.49 & 5.15 & & & & \\
\hline H8 & $\mathrm{SA}$ & 66 & 22.89 & 5.09 & \multirow{6}{*}{8543.43} & \multirow{6}{*}{1423.91} & \multirow{6}{*}{28.60} & \multirow{6}{*}{$.000^{*}$} \\
\hline Unpopular & Oman & 23 & 23.42 & 6.75 & & & & \\
\hline \multirow[t]{4}{*}{ Choice } & UAE & 10 & 21.58 & 5.18 & & & & \\
\hline & Kuwait & 5 & 25.20 & 2.45 & & & & \\
\hline & Bahrain & 13 & 22.62 & 7.09 & & & & \\
\hline & Qatar & 14 & 21.39 & 5.04 & & & & \\
\hline H9 & SA & 66 & 16.18 & 7.75 & \multirow{6}{*}{4231.25} & \multirow{6}{*}{705.21} & \multirow{6}{*}{12.09} & \multirow{6}{*}{$.000^{*}$} \\
\hline Avoidance & Oman & 23 & 17.67 & 7.61 & & & & \\
\hline \multirow[t]{4}{*}{ Similarity } & UAE & 10 & 15.40 & 4.38 & & & & \\
\hline & Kuwait & 5 & 18.24 & 6.58 & & & & \\
\hline & Bahrain & 13 & 18.86 & 5.60 & & & & \\
\hline & Qatar & 14 & 13.19 & 5.69 & & & & \\
\hline
\end{tabular}




\section{Conclusion/ Discussion}

This study was designed to understand how consumers within the GCCC are different in their need for uniqueness. Applying Hofstede \& Hofstede's (2001) model of national culture to GCCC citizens indicated that power distance correlates positively with the need for uniqueness while indulgence correlates negatively with the need for uniqueness. As previous studies have indicated a negative strong relationship between power distance dimension and the need for uniqueness among other countries, this study confirmed a strong positive relationship between the power distance and the need for uniqueness in GCCC. When enterprises, retailer and/or marketers choose to expand their business interest to the GCCC, business owners may achieve greater profits by marketing through informal marketing channels such as celebrity and words-of-mouth rather than traditional ways used in other countries. On the other hand, this study indicated the strong negative relationship with the indulgence. This means consumers in the GCCC with less time and chance for fun and an enjoyable life, consume more new products. The reason for that may be that shopping is the way that people of the GCCC tend to have fun, nothing else. For businesses, reaching the consumers of the GCCC regarding shopping strategies, added time and patience with product sales may help reach higher profits. Additionally, strong considerations regarding visual merchandising aspects would help the consumer get more in touch with the products and experience them more fully before making a purchase.

\subsection{Implications}

This study also confirms the impact of culture on the need for uniqueness of the people of the GCCC. When GCCC consumers feel more pressure from authorities and experience less fun activities, they tend to shop and buy more commodities in order to distinguish themselves. How do they express themselves through shopping exactly? This study reports that the GCCC consumers tend to express their need for uniqueness through adapting to unpopular product choices which differ from the majority rather than buying products that are considered uncreative. They also tend to avoid buying products that are similar to the items of the majority. Providing uniqueness of product to the countries would benefit marketers and retailers in this area.

For retailers, fad or unique items may be accepted in the GCCC, new items will be accepted on a short timeline as well compared to other countries. However, the life cycle of the product may be short. The people of the GCCC are not interested in expressing themselves through thinking outside of the box, for example buying second hands items, or redesigning their old items. Thus, business owners in these countries should provide the market with new items frequently to attract GCCC consumers. In addition, it is crucial for retailers and business owners to adopt renewed and interesting visual merchandising strategies to attract GCCC consumers during their leisure time spent a majority of the time shopping.

\subsection{Limitations}

Due to the fact that the sample population in this study is majority women the results could be skewed. The lacking numbers regarding other countries outside of Saudi Arabia could also be of concern. The researchers call for future research to be more demographically synthesized but believe the topic and findings are of importance for such a new and critical rea of focus. Findings of this study provide insights regarding the GCCC region. Retailers and brands should take note of this research and be sensitive to the influence of the power distance and the indulgence aspects of cultural of this wealthy region. Future research should investigate the impact of the consumption pattern of the people of the GCCC and its impact on the environment. The well-being of next generations of the GCCC is threatened as people tend to consume more new products and ignore the recycling activities of the old products.

\section{References}

Amadeo, K. (2016). Gulf cooperation council countries: Sixe rich countries that own the world's oil. Retrieved from https://www.thebalance.com/gulf-cooperation-council-3306357

Asshidin, N. H. N., Abidin, N., \& Borhan, H. B. (2016). Consumer Attitude and Uniqueness towards International Products. Procedia Economics and Finance, 35, 632-638. https://doi.org/10.1016/S2212-5671(16)00077-0

Bolter, A. (2011). “The Learning Curve”, Private Banking and Wealth Management, Special Report.

Consultancy.uk. (2014). Bain: Top 11 luxury markets and cities of the globe. Retrieved from http://www.consultancy.uk/news/937/bain-top-11-luxury-markets-and-cities-of-the-globe

Euromonitor. (2017). Luxury goods in the United Arab Emirates. Market Reports Center. Retrieved from https://marketreportscenter.com/reports/433960/luxury-goods-in-the-united-arab-emirates 
Fromkin, H. L., \& Snyder, C. R. (1980). The search for uniqueness and valuation of scarcity. Social exchange (pp. 57-75). New York: Springer US.

Hofstede, G. H., \& Hofstede, G. (2001). Culture's consequences: Comparing values, behaviors, institutions and organizations across nations. Thousand Oaks: Sage.

Hofstede, G., Hofstede, G., \& Minkov, M. (2010). Cultural and organizations. New York NY: Mc Graw Hill.

Hofstede, G., Hofstede, G., Minkov, M., \& Vinken, H. (2013). Values Survey Module 2013 Manual.

Hsu, Y., Hsu, L., \& Yeh, C. W. (2010). A cross-cultural study on consumers' level of acceptance toward marketing innovativeness. African Journal of Business Management, 4(6), 12-15.

Imhoff, R., \& Erb, H. P. (2009). What motivates nonconformity? Uniqueness seeking blocks majority influence. Personality and Social Psychology Bulletin, 35(3), 309-320. https://doi.org/10.1177/0146167208328166.

Knight, D. K., \& Young Kim, E. (2007). Japanese consumers' need for uniqueness: Effects on brand perceptions and purchase intention. Journal of Fashion Marketing and Management: An International Journal, 11(2), 270-280. https://doi.org/10.1108/13612020710751428

Kunz, G. I., \& Garner, M. B. (2011). Going global. The Textile and Apparel Industry, Fairchild.

Lynn, M., \& Harris, J. (1997). The desire for unique consumer products: A new individual differences scale. Psychology \& Marketing, 601-616. https://doi.org/10.1002/(SICI)1520-6793(199709)14:6<601::AID-MAR5>3.0.CO;2-B

Marx, K. (1867). Das Kapital: kritik der politischen ökonomie. Verlag von Otto Meisner, Germany, 1885, 1894.

Miremadi, A., Fotoohi, H., Sadeh, F., Tabrizi, F., \& Javidigholipourmashhad, K. (2011). The Possible Effects of Need for Uniqueness's Dimensions on Luxury Brands: Case of Iran and UAE. International Journal of Marketing Studies, 3(3), 151. http://dx.doi.org/10.5539/ijms.v3n3p151

Simonson, I., \& Nowlis, S. M. (2000). The role of explanations and need for uniqueness in consumer decision making: Unconventional choices based on reasons. Journal of Consumer Research, 27(1), 49-68. https://doi.org/10.1086/314308

Takada, H., \& Jain, D. (1991). Cross-national analysis of diffusion of consumer durable goods in Pacific Rim countries. The Journal of Marketing, 48-54. https://doi.org/10.2307/1252237

Tawfiq, W. A., \& Ogle, J. P. (2013). Constructing and presenting the self through private sphere dress: an interpretive analysis of the experiences of Saudi Arabian women. Clothing and Textiles Research Journal, 31(4), 275-290. https://doi.org/10.1177/0887302X13504031

Tian, K. T., Bearden, W. O., \& Hunter, G. L. (2001). Consumers' need for uniqueness: Scale development and validation. Journal of Consumer Research, 28(1), 50-66. https://doi.org/10.1086/321947

Vel, K. P., Captain, A., Al-Abbas, R., \& Al Hashemi, B. (2011). Luxury buying in the United Arab Emirates.

Workman, J. E., \& Kidd, L. K. (2000). Use of the need for uniqueness scale to characterize fashion consumer $\begin{array}{lllll}\text { groups. } \quad \text { Clothing and } & \text { Rextiles } 27-236 .\end{array}$ https://doi.org/10.1177/0887302X0001800402

\section{Copyrights}

Copyright for this article is retained by the author, with first publication rights granted to the journal.

This is an open-access article distributed under the terms and conditions of the Creative Commons Attribution license (http://creativecommons.org/licenses/by/4.0/). 